\title{
Health literacy of Dutch adults: a cross sectional survey
}

Iris van der Heide ${ }^{1,2^{*}}$, Jany Rademakers ${ }^{2}$, Maarten Schipper ${ }^{3}$, Mariël Droomers ${ }^{4}$, Kristine Sørensen ${ }^{5}$ and Ellen Uiters ${ }^{1}$

\begin{abstract}
Background: Relatively little knowledge is available to date about health literacy among the general population in Europe. It is important to gain insights into health literacy competences among the general population, as this might contribute to more effective health promotion and help clarify socio-economic disparities in health. This paper is part of the European Health Literacy Survey (HLS-EU). It aims to add to the body of theoretical knowledge about health literacy by measuring perceived difficulties with health information in various domains of health, looking at a number of competences. The definition and measure of health literacy is still topic of debate and hardly any instruments are available that are applicable for the general population. The objectives were to obtain an initial measure of health literacy in a sample of the general population in the Netherlands and to relate this measure to education, income, perceived social status, age, and sex.

Methods: The HLS-EU questionnaire was administered face-to-face in a sample of 925 Dutch adults, during July 2011. Perceived difficulties with the health literacy competences for accessing, understanding, appraising and applying information were measured within the domains of healthcare, disease prevention and health promotion. Multiple linear regression analyses were applied to explore the associations between health literacy competences and education, income, perceived social status, age, and sex.

Results: Perceived difficulties with health information and their association with demographic and socio-economic variables vary according to the competence and health domain addressed. Having a low level of education or a low perceived social status or being male were consistently found to be significantly related to relatively low health literacy scores, mainly for accessing and understanding health information.
\end{abstract}

Conclusions: Perceived difficulties with health information vary between competences and domains of health. Health literacy competences are associated with indicators of socio-economic position and with the domain in which health information is provided.

Keywords: Health literacy, Socio-economic position, General population, Netherlands

\section{Background}

During the past decades, there has been a growing interest in the concept of health literacy, accompanied by the increased emphasis on the role and responsibility of citizens in health and healthcare [1-3]. The importance of health literacy as a topic of research has been pointed out by a number of studies that suggest health literacy might play a significant role in maintaining or improving

\footnotetext{
* Correspondence: Iris.van.der.Heide@rivm.nl

${ }^{1}$ Centre for Nutrition, Prevention and health Services, National Institute for

Public Health and the Environment, Bilthoven, Netherlands

${ }^{2}$ NIVEL, Netherlands Institute for Health Services Research, Utrecht,

Netherlands

Full list of author information is available at the end of the article
}

health and could be an unexplored predictor of health disparities [4-6]. The aim of the present study is to contribute to the theoretical knowledge being built up about health literacy. An initial insight into the health literacy of the general population will therefore be provided and its association with demographic and socio-economic characteristics will be examined.

An important issue regarding health literacy research is the ongoing debate on the definition and scope of health literacy $[1,7,8]$. Within this discourse, two main approaches can be distinguished, namely the 'clinical' approach and the 'public health' approach [7,9]. Key elements of definitions from a clinical perspective

\section{Biomed Central}

(c) 2013 van der Heide et al.; licensee BioMed Central Ltd. This is an Open Access article distributed under the terms of the Creative Commons Attribution License (http://creativecommons.org/licenses/by/2.0), which permits unrestricted use, distribution, and reproduction in any medium, provided the original work is properly cited. 
include elements of behaviour that mainly reflect individual competences needed to function in the role of patient within a healthcare environment $[8,10,11]$. Studies that define health literacy from a public health point of view extend the concept by addressing the public at large instead of patients and including dimensions beyond the medical context, such as the workplace, political arena or home $[4,12]$. Most research on health literacy stems from the clinical perspective. Additionally, research that stems from the public health perspective has mainly been carried out outside Europe, although there has been some recently in Switzerland [4,13-15]. Especially in the European situation, little is known about health literacy outside a clinical setting and among the general population.

The present paper is based on data gathered in the Netherlands in the context of the European Health Literacy Survey (HLS-EU). A research consortium with members from Austria, Bulgaria, Germany, Greece, Ireland, the Netherlands, Poland and Spain made joint efforts to develop a common tool to measure health literacy in the general population [16,17]. This tool was based on a common definition and conceptual model of health literacy (see Additional file 1). Other measurement tools often measured health literacy as a unidimensional concept by focusing on text comprehension or word recognition [18-20]. The HLS-EU addresses health literacy as a multidimensional concept, embracing competences other than reading skills. More precisely, health literacy is measured as people's perceived ability to access, understand, appraise, and apply health information. This measure is not limited to a single domain, but involves three domains of health, namely healthcare, disease prevention and health promotion, which have been clarified in more detail elsewhere [17].

In addition to the development of an instrument (HLS-E-Q), the HLS-EU survey gathered information on socio-economic and demographic characteristics. Previous studies suggest that low health literacy is more prevalent among people with low levels of education and low incomes and those who are older [5,6,21-24]. As far as is known, perceived social status, an increasingly-used measure for socio-economic status, has not been studied in relation to health literacy before, but was included in this study as well [25]. As regards health literacy of men and women, the studies report varying results. Whereas some found no relationship [4,25], others report that one of the sexes is more likely to have low health literacy $[26,27]$.

Better insights into the relationships between demographic and socio-economic characteristics and health literacy will help identify vulnerable groups with limited health literacy who are therefore possibly at risk of being in poor health [28]. Specific questions in our study therefore are 1) to what extent do adults perceive difficulties with the health literacy competences of accessing, understanding, appraising and applying health information in the domains of healthcare, disease prevention and health promotion and 2) to what extent are these competences related to demographic and socioeconomic characteristics?

\section{Methods}

\section{Study design and data collection}

A stratified random sampling design was applied to the Dutch population aged 15 years or older, in accordance with the Eurobarometer methodology [29]. The sample was stratified according to province and within provinces according to urban and rural areas, leading to a probability of inclusion that was proportional to population size and density. In the first stage, 699 areas were defined, including a total selection of 24,942 addresses. Households were selected randomly in each of these areas. In each household, one respondent was recruited over the phone or contacted by e-mail, following the closest birthday rule. During July 2011, 221 interviewers administered the questionnaires face-to-face with the pre-recruited respondents in people's homes. The questionnaires were conducted in Dutch. A total of 2817 people were contacted of whom 1794 were not willing to participate, leading to a sample of 1023 participants (response rate 36\%). It was decided to focus the analyses on persons aged 25 years or older, as income, education and social status are more stable after this age, resulting in a final sample of 925 adults.

\section{Assessment of variables Health literacy}

The questionnaire for measuring health literacy in the general population in Europe (the HLS-EU-Q) was developed collectively by the HLS-EU consortium [16]. The questionnaire was based on the definition and conceptual model developed within the HLS-EU consortium, which are presented in an Additional file 1 and described in detail elsewhere [17]. Table 1 presents four examples of items from the HLS-EU-Q. For the full questionnaire, please contact the fifth author (KS). The HLS-EU-Q was pre-tested for understandability and completeness, using focus groups in Greece, Ireland and the Netherlands ( $\mathrm{n}=6$ in each country) and face-to-face interviews in Ireland and the Netherlands $(n=50$ in each country). Extensive information on the development and pre-testing of the HLS-EU-Q is described elsewhere $[17,30]$. The final questionnaire, as illustrated in Table 2, measured health literacy across three domains of health, namely healthcare, disease prevention and health promotion. Within these domains, the questionnaire focused on (a) accessing, or the ability to seek, find and 
Table 1 Examples of HLS-EU questionnaire items per competence and domain

\begin{tabular}{ll}
\hline Competence / health domain & On a scale from very easy to very difficult, how easy wouldyou say it is for you to... \\
\hline accessing / healthcare & $\ldots$. find out what to do in case of a medical emergency? \\
understanding / healthcare & $\ldots$. understand what your doctor says to you? \\
appraising / disease prevention & $\ldots$..judge which vaccinations you may need? \\
applying / health promotion & $\ldots$..make decisions to improve your health? \\
\hline
\end{tabular}

obtain health information (13 items); (b) understanding, or the ability to comprehend health information (11 items); (c) appraising, or the ability to interpret, filter, judge and evaluate health information (12 items); and (d) applying, or the ability to communicate and use the information to maintain and improve health (11 items). Answer categories on the health literacy questions (all phrased similarly to "On a scale from very easy to very difficult, how easy would you say it is to understand why you need health screenings?") were on a 4-point Likerttype scale ranging from $1=$ very difficult, $2=$ fairly difficult to 3 = fairly easy and $4=$ very easy. A "don't know" answer option was not provided, but only used when stated spontaneously. This response was coded as a missing value. In order to get an initial insight into perceived difficulties, answers were combined to sum scores per competence and a distinction was made between those who perceive numerous difficulties and those who perceive few difficulties. Those respondents with the lowest scores on all four competences (scores below the first quartile for accessing, understanding, appraising as well as applying) were categorized as perceiving numerous difficulties; those with the highest scores were considered to perceive few difficulties (scores above the third quartile for accessing, understanding, appraising as well as applying). This was done per domain as well as over all domains.

\section{Demographic and socio-economic characteristics}

The following demographic and socio-economic characteristics were analysed: sex, age, educational level, net household income per month and social status (see
Table 3). Age was measured and analysed as a continuous variable. Educational level was measured on a sixpoint scale. For the purpose of the analyses, education was categorized into 1) no education or primary education, 2) lower secondary education, 3) (upper) secondary education or post-secondary non-tertiary education (including vocational education), or 4) tertiary education (bachelor's degree or higher). Net monthly household income was measured on a ten-point scale. In the analyses, income was recoded into quartiles 1) less than 1850 euros, 2) 1850 - 2400 euros, 3) 2400 - 3600 euros, 4) 3600 euros or more. As regards perceived social status: there is evidence that this self-reported variable reflects standard markers of socio-economic status such as education and income, as well as having the advantage of being seen as a more accurate measure of social position [26]. In this study, perceived social status was assessed by the answer to the question: "On the following scale, step 1 corresponds to 'the lowest level in society'; step 10 corresponds to 'the highest level in society'. Could you tell me which step you would say you were on?" This item stemmed from the Eurobarometer [31]. Table 3 presents the scores in the categories low (1-4), medium $(5,6)$ and high (7-10), continuous scores were included in the analyses.

\section{Statistical analyses}

To explore reliability and internal consistency of the questionnaire, factor analyses (principal component analyses with promax rotation: data not shown) were performed and Cronbach's alphas were calculated. The internal consistency of the health literacy items

Table 2 Competences and domains included in the HLS-EU questionnaire

\begin{tabular}{|c|c|c|c|}
\hline \multirow[t]{2}{*}{ Competences } & \multicolumn{3}{|l|}{ Domains } \\
\hline & Healthcare & Disease prevention & Health promotion \\
\hline Accessing & $\begin{array}{l}\text { The ability to seek, find and obtain } \\
\text { information on medical or clinical issues. }\end{array}$ & $\begin{array}{l}\text { The ability to seek, find and obtain } \\
\text { information on risk factors for health. }\end{array}$ & $\begin{array}{l}\text { The ability to seek, find and obtain } \\
\text { information on determinants of health. }\end{array}$ \\
\hline Understanding & $\begin{array}{l}\text { The ability to comprehend information on } \\
\text { medical or clinical issues. }\end{array}$ & $\begin{array}{l}\text { The ability to comprehend information } \\
\text { on risk factors and derive meaning. }\end{array}$ & $\begin{array}{l}\text { The ability to comprehend information on } \\
\text { determinants of health and derive meaning. }\end{array}$ \\
\hline Appraising & $\begin{array}{l}\text { The ability to interpret, filter, judge, and } \\
\text { evaluate information on medical or clinical } \\
\text { issues. }\end{array}$ & $\begin{array}{l}\text { The ability to interpret, filter, judge, and } \\
\text { evaluate information on risk factors. }\end{array}$ & $\begin{array}{l}\text { The ability to interpret, filter, judge, and } \\
\text { evaluate information on determinants of } \\
\text { health. }\end{array}$ \\
\hline Applying & $\begin{array}{l}\text { The ability to communicate and use } \\
\text { information on medical or clinical issues to } \\
\text { make informed decision. }\end{array}$ & $\begin{array}{l}\text { The ability to communicate and use } \\
\text { information on risk factors to make } \\
\text { informed decisions. }\end{array}$ & $\begin{array}{l}\text { The ability to communicate and use } \\
\text { information on determinants of health to } \\
\text { make informed decisions. }\end{array}$ \\
\hline
\end{tabular}


Table 3 Characteristics study participants

\begin{tabular}{|c|c|c|c|c|c|c|}
\hline \multirow[t]{2}{*}{ Characteristics } & \multicolumn{2}{|c|}{ Total $(n=925)$} & \multicolumn{2}{|c|}{ Men $(n=439)$} & \multicolumn{2}{|c|}{ Women $(n=486)$} \\
\hline & $\%$ & $\mathbf{n}$ & $\%$ & $\mathbf{n}$ & $\%$ & $\mathrm{n}$ \\
\hline \multicolumn{7}{|l|}{ Age in categories } \\
\hline $25-34$ & 13.1 & (121) & 14.4 & (63) & 11.9 & (58) \\
\hline $35-44$ & 14.5 & (134) & 13.9 & (61) & 15.0 & (73) \\
\hline $45-54$ & 18.7 & (173) & 16.9 & (74) & 20.4 & (99) \\
\hline $55-64$ & 16.0 & (148) & 15.3 & (67) & 16.7 & (81) \\
\hline $65-74$ & 19.4 & (179) & 21.2 & (93) & 17.7 & (86) \\
\hline $75-84$ & 15.1 & $(140)$ & 15.3 & (67) & 15.0 & (73) \\
\hline $85+$ & 3.2 & (30) & 3.2 & (14) & 3.3 & (16) \\
\hline Missing values & 0 & (0) & 0 & (0) & 0 & (0) \\
\hline \multicolumn{7}{|l|}{ Highest completed education level } \\
\hline No education or primary education & 6.9 & (64) & 5.9 & (26) & 7.8 & (38) \\
\hline Lower secondary education & 26.2 & $(242)$ & 26.0 & $(115)$ & 26.1 & $(127)$ \\
\hline (Upper or post-) secondary non-tertiary education & 29.1 & (269) & 29.0 & $(127)$ & 29.2 & $(142)$ \\
\hline Tertiary education (bachelor's degree or higher) & 37.8 & $(350)$ & 39.0 & $(171)$ & 36.8 & $(179)$ \\
\hline Missing values & 1.0 & (9) & 0.7 & (3) & 1.2 & (6) \\
\hline \multicolumn{7}{|l|}{ Household net income per month in euros } \\
\hline$<1850$ & 35.3 & (326) & 29.6 & (130) & 40.3 & (196) \\
\hline $1850-2400$ & 16.8 & (155) & 17.1 & (75) & 16.5 & (80) \\
\hline $2400-3600$ & 29.5 & (273) & 32.1 & $(141)$ & 27.2 & (132) \\
\hline 3600 or $>$ & 18.5 & (171) & 21.2 & (93) & 16.0 & (78) \\
\hline Missing values & 16.2 & (150) & 16.4 & (72) & 16.0 & (78) \\
\hline \multicolumn{7}{|l|}{ Perceived social status } \\
\hline Low & 3.7 & (35) & 3.6 & (16) & 3.8 & (19) \\
\hline Medium & 24.2 & (224) & 22.8 & $(100)$ & 25.5 & (124) \\
\hline High & 72.0 & (666) & 73.6 & (323) & 70.6 & (343) \\
\hline Missing values & 2.7 & (25) & 3.4 & (15) & 2.1 & (10) \\
\hline
\end{tabular}

(measuring accessing, understanding, appraising and applying) was satisfactory (Cronbach's $\alpha=0.84,0.83,0.85$ and 0.78 respectively). In accordance with the domains defined beforehand, factor analyses distinguished between the factors 'healthcare', 'disease prevention' and 'health promotion' for the competences 'accessing,' 'understanding' and 'applying'. With regard to appraising, the factor analysis identified only two factors, which were labelled 'healthcare and disease prevention' and 'health promotion', combining the items designed to measure health literacy in healthcare and disease prevention. The reliability and internal consistency analyses justified the calculation of sum scores for each combination of competence and domain. Descriptive statistics in terms of sum scores and means per item (sum score / number of items) were performed to answer the first research question. Multiple linear regression analyses were used to answer the second research question concerning the associations between health literacy and demographic and socio-economic characteristics. For each competence within each domain, a multiple linear regression analysis was performed in SAS 9.2, including the means per item for each health literacy competence, education, income, social status, age, and sex.

\section{Missing values}

The dataset contained missing values concerning education $(1 \%, \mathrm{~N}=9)$, subjective social status $(3 \%, \mathrm{~N}=25)$ and income $(16 \%, \mathrm{~N}=150)$, as presented in Table 3. Table 4 shows the missing values per health literacy domain and competence. The characteristics of the missing values on the health literacy competences are described in Additional file 2. The method of multiple imputations by chained equations was used to handle the presence of missing values in the study data, as these were not missing completely at random (see Additional file 2 for more details on the missing data) [32]. Following this procedure, the original data set was completed 20 times. 
Table 4 Descriptive statistics per health literacy competence and domain $(N=925)^{\text {a }}$

\begin{tabular}{|c|c|c|c|c|c|c|c|}
\hline \multirow{2}{*}{ Competence domain } & \multirow{2}{*}{ Items } & \multirow{2}{*}{$\begin{array}{l}\text { Missings } \\
\text { (n) }\end{array}$} & \multirow{2}{*}{$\begin{array}{c}\text { Mean } \\
\text { (SD) }\end{array}$} & \multirow{2}{*}{$\begin{array}{l}\text { Mean per } \\
\text { item (SD) }\end{array}$} & \multicolumn{3}{|c|}{ Mean per item per quartile } \\
\hline & & & & & 25 & 50 & 75 \\
\hline Accessing & 11 & 231 & $35.2(5.2)$ & $3.2(0.5)$ & 2.6 & 3.2 & 3.7 \\
\hline Healthcare & 3 & 82 & $9.7(1.8)$ & $3.2(0.6)$ & 2.7 & 3.3 & 3.4 \\
\hline Disease prevention & 6 & 122 & $20.3(3.1)$ & $3.4(0.5)$ & 2.8 & 3.4 & 4.0 \\
\hline Health promotion & 2 & 118 & $5.1(1.7)$ & $2.6(0.8)$ & 1.7 & 2.5 & 3.9 \\
\hline Understanding & 11 & 157 & $36.8(4.9)$ & $3.3(0.5)$ & 2.8 & 3.4 & 3.9 \\
\hline Healthcare & 4 & 58 & $13.5(2.1)$ & $3.4(0.5)$ & 2.8 & 3.4 & 3.9 \\
\hline Disease prevention & 3 & 29 & $10.8(1.5)$ & $3.6(0.5)$ & 3.0 & 3.7 & 4.0 \\
\hline Health promotion & 4 & 108 & $12.5(2.6)$ & $3.1(0.7)$ & 2.4 & 3.2 & 3.9 \\
\hline Appraising & 12 & 219 & $36.7(5.9)$ & $3.1(0.5)$ & 2.5 & 3.1 & 3.7 \\
\hline Healthcare and prevention & 9 & 201 & $27.0(4.8)$ & $3.0(0.5)$ & 2.4 & 3.0 & 3.6 \\
\hline Health promotion & 3 & 47 & $9.8(1.9)$ & $3.3(0.6)$ & 2.7 & 3.5 & 4.0 \\
\hline Applying & 9 & 196 & $28.9(4.2)$ & $3.2(0.5)$ & 2.7 & 3.2 & 3.8 \\
\hline Healthcare & 3 & 16 & $10.8(1.5)$ & $3.6(0.5)$ & 3.0 & 3.7 & 4.0 \\
\hline Disease prevention & 2 & 64 & $5.7(1.7)$ & $2.9(0.8)$ & 1.8 & 2.8 & 3.8 \\
\hline Health promotion & 4 & 155 & $12.4(2.7)$ & $3.1(0.7)$ & 2.3 & 3.1 & 3.8 \\
\hline
\end{tabular}

a Scores ranged from 'very difficult' (lowest score) to 'very easy' (highest score).

${ }^{b}$ Number of missing values per competence and domain before multiple imputation.

Each imputed dataset was analysed separately and the outcomes of each analysis were combined according to Rubin's rules to obtain the outcome of the whole analysis, which incorporates the uncertainty due to the missing values [31]. The imputations were done in $R$ 2.14.0, with use of the mice package $[31,32]$. Recent studies have shown that this technique provides less biased results compared to a complete case analysis and is considered to be the state-of-the-art method for dealing with missing data $[33,34]$.

\section{Results}

The sample distribution in terms of sex, education and income (Table 3) was in accordance with the distribution in the Dutch population (not tabulated) [35]. Adults aged 65 years or older were overrepresented and adults between 25 and 39 years of age were underrepresented in the studied population [35].

Concerning the four competences of accessing, understanding, appraising and applying health information, the mean scores per item are all close to 3 (equal to being perceived as easy) where the maximum score is 4 (being perceived as very easy) (see Table 4). The mean score per item (over all domains) is lowest for appraising information (3.1) and highest for understanding information (3.4). The scores presented in Table 4 imply that perceived difficulties vary between the health domains. Accessing health information seems to be perceived as more difficult in the domain of health promotion (mean score per item is 2.6) than in the domain of disease prevention (mean score per item is 3.4).
Comparing the health domains of healthcare, disease prevention and health promotion, the mean score per item (over all competences) was lowest in the domain of health promotion (3.0) and highest in the domain of healthcare (3.3) (not tabulated). Within the domain of healthcare, $9.6 \%$ of Dutch adults $(\mathrm{N}=89)$ perceived numerous difficulties, whereas $14.4 \%(\mathrm{~N}=134)$ perceived few difficulties (not tabulated). Furthermore, $4.8 \%$ $(\mathrm{N}=44)$ perceived numerous difficulties with information on disease prevention and $12.0 \% \quad(\mathrm{~N}=111)$ perceived few difficulties (not tabulated). Finally, 9.2\% $(\mathrm{N}=86)$ perceived numerous difficulties with information on health promotion, whereas $8.6 \% \quad(\mathrm{~N}=79)$ perceived few difficulties (not tabulated). Looking at the respondents who perceived numerous difficulties across all three health domains, it appeared that this was the case for $10.4 \%(\mathrm{~N}=96)$ of the respondents (those scoring below the first quartile on accessing, understanding, appraising as well as applying). Subsequently, $11.9 \%$ $(\mathrm{N}=110)$ of the respondents perceived few difficulties (scores above the third quartile on accessing, understanding, appraising as well as applying) across all domains (not tabulated).

As regards the associations of socio-economic and demographic variables with health literacy, none of the included socio-economic and demographic variables was consistently associated with all health literacy competences and domains addressed. Overall, it was found that people with a lower level of education, or who reported a lower perceived social status or were male perceived more difficulties with health literacy. 
Taking into account all demographic and socioeconomic variables, the results of the multiple regression analyses indicate a clear association of health literacy with level of education (see Table 5). The group with the lowest educational level in particular had significantly lower health literacy scores compared to the group with the highest educational level, indicating that the former group experienced more difficulties. However, this association differed between the competences addressed and was most obvious for the competences of accessing and understanding health information in the domains of healthcare and disease prevention. In the domain of health promotion the association was most obvious for understanding health information. With regard to accessing and understanding, the lowest income group was also found to have lower health literacy scores compared to those with the highest incomes. However, this was only found in the healthcare domain (Table 5). In addition to the socio-economic indicators of education and income, social status was also found to be related to health literacy. The higher the self-reported social status, the higher the health literacy scores, except for accessing information on healthcare and health promotion and applying information on disease prevention. Age was found to be significantly associated with health literacy scores in some domains. Like education, age was mainly significantly related to accessing and understanding health information, but also to some extent to appraising health information in the domain of health promotion. In terms of sex, men perceived more difficulties than women, except for accessing and applying in the domain of health promotion.

\section{Discussion}

The aim of this study was to contribute to theoretical knowledge being built up about health literacy and to provide an initial insight into the health literacy of the general population and its associations with demographic and socio-economic characteristics. For that purpose, the Dutch data from the European Health Literacy Survey (HLS-EU) was used [16,17]. The data provided information on health literacy reflected by the competences of accessing, understanding, appraising and applying information in the domains of healthcare, disease prevention and health promotion. The findings of this study suggest that the health literacy scores in a sample of the Dutch general population vary between the four different competences studied. This is consistent with findings from other countries participating in the HLS-EU project [16]. Furthermore, the perceived difficulties with these competences differ according to the health domain which they appeal to. For example, accessing information on healthcare was perceived more difficult than accessing information on disease prevention. It seems that the level of health literacy in the general population is associated with the setting in which the health information is provided.

In terms of health outcomes, low health literacy scores in the three domains and over the four competences might lead to suboptimal health in various ways. For example, those who perceive difficulties with accessing and understanding information about screening might unintentionally be excluded from screening programmes [36,37]. Moreover, those who perceive difficulties understanding their medication leaflets might not be able to use their medication correctly [38].

As to the extent to which health literacy competences are associated with demographic and socio-economic characteristics, the results indicate that lower health literacy is associated with lower socio-economic position, in accordance with the literature [4-6,21-23]. Educational and income-related differences in health literacy were found in particular in accessing and understanding health information. These can be considered as basic health literacy competences, related to functional health literacy as described by Nutbeam [7]. Differences between educational levels or income groups were found to a lesser extent for appraising and applying health information, which are more complex competences related to the concept of critical health literacy [7]. This indicates that those who are highly educated or have a high income do not have an advantage on the more complex competences of appraising and applying compared to those who are low educated or have a low income, as is the case for the basic competences of accessing and understanding. It is recommended that these aspects and the aspect of critical health literacy should be addressed in future research.

One striking finding is that perceived social status seems to affect all health literacy competences. This leads to the assumption that this subjective indicator of socio-economic status differs, in relation to health literacy, from the objective indicators of education and income. Given the importance that has been placed on the association between health literacy and socioeconomic status, this seems an important topic for future research $[6,7]$.

This study found mixed results regarding the association between health literacy and age. A negative association was found between age and accessing information on healthcare and disease prevention and understanding information on disease prevention and health promotion, indicating that increasing age is accompanied by lower levels of health literacy on these specific dimensions. This seems in accordance with findings of former studies $[4,6,21,22,24]$. It has been suggested that the negative association between age and health literacy might be attributable to an age related decline of the 
Table 5 Associations between socio-economic and demographic characteristics and health literacy competences *

\begin{tabular}{|c|c|c|c|c|c|c|c|c|}
\hline \multirow[t]{2}{*}{ Healthcare } & \multicolumn{2}{|r|}{ Accessing } & \multicolumn{2}{|c|}{ Understanding } & \multicolumn{2}{|c|}{ Appraising $^{a}$} & \multicolumn{2}{|r|}{ Applying } \\
\hline & B & $95 \% \mathrm{Cl}$ & B & $95 \% \mathrm{Cl}$ & B & $95 \% \mathrm{Cl}$ & B & $95 \% \mathrm{Cl}$ \\
\hline \multicolumn{9}{|l|}{ Education (reference group: tertiary education) } \\
\hline No education or primary education & -0.2906 & $(-0.4653$ to -0.1160$)$ & -0.1949 & $(-0.3497$ to -0.0402$)$ & -0.0562 & $(-0.2098$ to 0.0974$)$ & -0.1576 & $(-0.3021$ to -0.0131$)$ \\
\hline Lower secondary education & -0.0464 & $(-0.1558$ to 0.0631$)$ & -0.1838 & $(-0.2772$ to -0.0904$)$ & -0.0074 & $(-0.1030$ to 0.0882$)$ & -0.0678 & $(-0.1556$ to 0.0200$)$ \\
\hline (Upper or post-) secondary education ${ }^{\mathrm{b}}$ & 0.0557 & $(-0.0430$ to 0.1544$)$ & -0.0587 & $(-0.1432$ to 0.0256$)$ & 0.0502 & $(-0.0368$ to 0.1371$)$ & -0.0431 & $(-0.1229$ to 0.0367$)$ \\
\hline \multicolumn{9}{|l|}{ Income (reference group: 3600 or more) } \\
\hline$<1850$ euros & -0.2294 & $(-0.3738$ to -0.0849$)$ & -0.1283 & $(-0.2444$ to -0.0121$)$ & -0.0418 & $(-0.1593$ to 0.0758$)$ & 0.0051 & $(-0.1082$ to 0.1183$)$ \\
\hline $1850-2400$ euros & -0.0771 & $(-0.2304$ to 0.0762$)$ & 0.0065 & $(-0.1192$ to 0.1322$)$ & 0.0267 & $(-0.1000$ to 0.1535$)$ & 0.0748 & $(-0.0432$ to 0.1927$)$ \\
\hline $2400-3600$ euros & -0.1426 & $(-0.2610$ to -0.0156$)$ & -0.0510 & $(-0.1562$ to 0.0542$)$ & -0.0554 & $(-0.1668$ to 0.0561$)$ & -0.0122 & $(-0.1187$ to 0.0944$)$ \\
\hline Social status & 0.0258 & ( 0.0067 to 0.0583 ) & 0.0371 & ( 0.0087 to 0.0654 ) & 0.0584 & ( 0.0295 to 0.0874 ) & 0.0308 & ( 0.0036 to 0.0581 ) \\
\hline Age (years) & -0.0039 & $(-0.0062$ to -0.0016$)$ & -0.0006 & $(-0.0025$ to 0.0014$)$ & 0.0010 & $(-0.0010$ to 0.0031$)$ & -0.0002 & $(-0.0021$ to 0.0017$)$ \\
\hline Male & 0.0810 & ( 0.0037 to 0.1582$)$ & 0.0799 & ( 0.0143 to 0.1455$)$ & 0.1415 & ( 0.0734 to 0.2096$)$ & 0.0673 & ( 0.0048 to 0.1298$)$ \\
\hline \multirow[t]{2}{*}{ Disease prevention } & \multicolumn{2}{|r|}{ Accessing } & \multicolumn{2}{|c|}{ Understanding } & & & \multicolumn{2}{|r|}{ Applying } \\
\hline & B & $95 \% \mathrm{Cl}$ & $B$ & $95 \% \mathrm{Cl}$ & & & B & $95 \% \mathrm{Cl}$ \\
\hline \multicolumn{9}{|l|}{ Education (reference group: tertiary education) } \\
\hline No education or primary education & -0.2418 & $(-0.3970$ to -0.0866$)$ & -0.2069 & $(-0.3489$ to -0.0650$)$ & & & -0.1217 & $(-0.3687$ to 0.1253$)$ \\
\hline Lower secondary education & -0.0989 & $(-0.1897$ to -0.0081$)$ & -0.1276 & $(-0.2137$ to -0.0415$)$ & & & -0.1028 & $(-0.2530$ to 0.0473$)$ \\
\hline (Upper or post-) secondary education ${ }^{b}$ & 0.0057 & $(-0.0772$ to 0.0887$)$ & -0.0152 & $(-0.0945$ to 0.0640$)$ & & & -0.0426 & $(-0.1807$ to 0.0955$)$ \\
\hline \multicolumn{9}{|l|}{ Income (reference group: 3600 or more) } \\
\hline$<1850$ euros & -0.1025 & $(-0.2175$ to 0.0125$)$ & -0.0516 & $(-0.1671$ to 0.0640$)$ & & & 0.0098 & $(-0.1840$ to 0.2037$)$ \\
\hline $1850-2400$ euros & 0.0506 & $(-0.0775$ to 0.1787$)$ & 0.0283 & $(-0.0927$ to 0.1493$)$ & & & 0.0402 & $(-0.1644$ to 0.2447$)$ \\
\hline $2400-3600$ euros & -0.0236 & $(-0.1288$ to 0.0816$)$ & -0.0138 & $(-0.1182$ to 0.0906$)$ & & & -0.0137 & $(-0.1995$ to 0.1721$)$ \\
\hline Social status & 0.0485 & ( 0.0208 to 0.0763 ) & 0.0313 & ( 0.0050 to 0.0577$)$ & & & 0.0242 & $(-0.0215$ to 0.0699$)$ \\
\hline Age (years) & -0.0028 & $(-0.0047$ to -0.0008$)$ & -0.0020 & $(-0.0039$ to -0.0001$)$ & & & -0.0011 & $(-0.0043$ to 0.0022$)$ \\
\hline Male & 0.1498 & ( 0.0849 to 0.2148 ) & 0.0839 & ( 0.0221 to 0.1457 ) & & & 0.1501 & ( 0.0427 to 0.2575 ) \\
\hline \multirow[t]{2}{*}{ Health promotion } & \multicolumn{2}{|r|}{ Accessing } & \multicolumn{2}{|c|}{ Understanding } & \multicolumn{2}{|r|}{ Appraising } & \multicolumn{2}{|r|}{ Applying } \\
\hline & B & $95 \% \mathrm{Cl}$ & B & $95 \% \mathrm{Cl}$ & B & $95 \% \mathrm{Cl}$ & B & $95 \% \mathrm{Cl}$ \\
\hline \multicolumn{9}{|l|}{ Education (reference group: tertiary education) } \\
\hline No education or primary education & -0.0779 & $(-0.3309$ to 0.1751$)$ & -0.3552 & $(-0.5395$ to -0.1709$)$ & -0.0881 & $(-0.2678$ to 0.0916$)$ & -0.1797 & $(-0.3774$ to 0.0181$)$ \\
\hline Lower secondary education & -0.0266 & $(-0.1798$ to 0.1266$)$ & -0.2267 & $(-0.3390$ to -0.1143$)$ & -0.0538 & $(-0.1642$ to 0.0565$)$ & -0.0170 & $(-0.1350$ to 0.1009$)$ \\
\hline (Upper or post-) secondary education ${ }^{b}$ & 0.0827 & $(-0.0578$ to 0.2232$)$ & -0.1013 & $(-0.2057$ to 0.0031$)$ & 0.0752 & $(-0.0259$ to 0.1762$)$ & -0.0037 & $(-0.1122$ to 0.1049$)$ \\
\hline \multicolumn{9}{|l|}{ Income (reference group: 3600 or more) } \\
\hline$<1850$ euros & -0.1036 & $(-0.2928$ to 0.0857$)$ & -0.0296 & $(-0.1669$ to 0.1077$)$ & 0.0510 & $(-0.0919$ to 0.1938$)$ & -0.0146 & $(-0.1656$ to 0.1364$)$ \\
\hline
\end{tabular}


Table 5 Associations between socio-economic and demographic characteristics and health literacy competences * (Continued)

\begin{tabular}{|c|c|c|c|c|c|c|c|c|}
\hline $1850-2400$ euros & 0.0513 & $(-0.1546$ to 0.2572$)$ & 0.0544 & $(-0.1003$ to 0.2090$)$ & 0.1318 & $(-0.0226$ to 0.2862$)$ & 0.0683 & $(-0.0928$ to 0.2293$)$ \\
\hline $2400-3600$ euros & -0.0363 & $(-0.2068$ to 0.1342$)$ & -0.0029 & $(-0.1331$ to 0.1273$)$ & 0.0048 & $(-0.1266$ to 0.1362$)$ & -0.0079 & $(-0.1510$ to 0.1351$)$ \\
\hline Social status & 0.0348 & $(-0.0120$ to 0.0815$)$ & 0.0543 & (0.0200 to 0.0886$)$ & 0.0686 & (0.0346 to 0.1027$)$ & 0.0629 & (0.0264 to 0.0994$)$ \\
\hline Age (years) & 0.0052 & (0.0018 to 0.0085$)$ & -0.0028 & $(-0.0053$ to -0.0004$)$ & 0.0063 & (0.0039 to 0.0087$)$ & 0.0006 & $(-0.0020$ to 0.0032$)$ \\
\hline Male & -0.0093 & $(-0.1183$ to 0.0996$)$ & 0.1975 & (0.1168 to 0.2782 ) & 0.1445 & (0.0651 to 0.2239$)$ & 0.0458 & $(-0.0398$ to 0.1314$)$ \\
\hline
\end{tabular}

* Analyses are based on mean per item; significant differences are printed in bold $(\mathrm{p}<0.05) .{ }^{\text {a }}$ Scores for appraising health information in the domain of healthcare and disease prevention were combined based on outcomes of factor analysis. ${ }^{b}$ Non-tertiary including vocational education. 
ability to perform cognitive tasks that require information processing [39]. Older adults seem to have more difficulty completing tasks that require reasoning or inferences from information presented to them, which has been linked to lower health literacy [39]. However, for accessing and appraising health information on health promotion, the present study suggest a positive association between age and health literacy, which seems contradicting to what was found in other studies. Further research is needed to examine why the direction of the association between age and health literacy differs between health literacy dimensions. The fact that elderly in the Netherlands are relatively high educated could be a possible contributor to the finding of mixed results.

With regard to the association between health literacy and sex, it was found that females perceive fewer difficulties with health information than men, especially in the domains of healthcare and disease prevention. No consistent pattern between sex and health literacy has been reported in the literature $[4,6,26,27]$.

The results of our study suggest that health information, whether it is about healthcare, disease prevention or health promotion, will most likely not have the same effect across the various socio-economic strata in the Dutch population. This implies that there could be benefits from improving the accessibility and usability of health information. In addition, a more challenging task seems to lie in making information easier to judge and to apply, as this calls upon more complex cognitive capacities [38]. However, to facilitate optimum information transfer, not only the information itself and the sender should be taken into account, but also the receiver. To this end, attention should be paid to possible ways of increasing the level of health literacy in the population, especially across lower socio-economic strata. For instance, it has been suggested that more attention should be paid to health literacy competences in school curricula [40].

\section{Strengths and limitations}

The health literacy measure that was used in this study differs from other measures, such as the Rapid Estimate of Adults Literacy in Medicine (REALM) and the Test of Functional Health Literacy in Adults (TOFHLA) $[18,20]$. These types of screening instruments largely measure health literacy in terms of reading skills applied in a clinical setting. The ability to read and understand health information is often referred to in the literature as 'functional health literacy' [2]. The HLS-EU-Q goes beyond measuring functional health literacy, as it focuses on multiple steps involved in information processing and decision-making in terms of health. It thereby provides an in-depth insight into health literacy as a multidimensional concept. Furthermore, the
HLS-EU-Q aims to encapsulate a broad scope of health by extending across three domains as well as going beyond a merely patient-related context. A valuable addition for further research might be the further exploration of other factors such as motivation to perform the four health literacy competences. This could influence information processing and decisionmaking and therefore seems relevant for the identification of those at risk of perceived difficulties with health information $[41,42]$.

An important strength of the methodology used in this study is that questionnaires were administered face-to-face. This facilitated the inclusion of adults with inadequate reading abilities. Adults who were not nationals of a European member state or had insufficient command of Dutch were excluded. Hence, the study does not reflect health literacy of adults with other ethnic backgrounds than European. To provide a rough indication of the proportion of the Dutch population that was not represented: in 2007, $8.3 \%$ of the Dutch population were born in a non-EU country [43]. It is likely that adults from ethnic minorities perceive more difficulties with health information, and hence the results might underestimate the health literacy skills of the adult population.

Another limitation is that elderly were overrepresented in the sample, which might have affected variables such as income or perceived social status and could possibly explain the small effect of income found in the current study, as the elderly account for a large proportion of the group of respondents with lower incomes. The educational level of older adults might have counterbalanced the effect of income on health literacy scores. In order to examine whether the findings of our study also yield for the subgroup of those aged 65 years or older, a subgroup analysis was performed, which indicated similar associations between socio-economic and demographic characteristics and health literacy (not tabulated). Therefore, the overrepresentation of elderly is not expected to have greatly affected the outcomes.

\section{Conclusions}

Health literacy can be addressed as a concept that involves multiple dimensions that seem to differ in their perceived difficulty. The current study shows that health literacy varies for the competences of accessing, understanding, appraising and applying information across the domains of healthcare, disease prevention and health promotion. The findings are consistent with other research: those with a low socio-economic position, primarily with a low education level and a low subjective social status, have lower health literacy than those with a high socio-economic position. 


\section{Consent}

This study did not fall within the scope of the Netherlands Medical Research Involving Human Subjects Act and therefore did not require ethical approval. All potential respondents were contacted via telephone and informed about the aim of the study and the use of the data for analyses and publication. Participation was voluntary and potential respondents could opt out from the study at any moment. By participating respondents consented to the research procedure.

\section{Additional files}

Additional file 1: Definition and integrated model of health literacy. Additional file 2: Characteristics missing values health literacy competences.

\section{Competing interests}

The authors declare that they have no competing interests.

\section{Authors' contributions}

All authors made significant contributions to the conception of this study. IH analysed the data and drafted the manuscript with contributions of EU, JR, MD and KS. MS contributed to the data analysis and interpretation. All authors read and approved the final manuscript.

\section{Acknowledgements}

This research is related to the HLS-EU project that is supported by grant 2007-113 from the European Commission, and co-financed by the Dutch Ministry of Health, Welfare and Sports.

\section{Author details \\ ${ }^{1}$ Centre for Nutrition, Prevention and health Services, National Institute for Public Health and the Environment, Bilthoven, Netherlands. ${ }^{2}$ NIVEL, Netherlands Institute for Health Services Research, Utrecht, Netherlands. ${ }^{3}$ Department of Statistics, Mathematical Modelling and Data Logistics, National Institute for Public Health and the Environment, Bilthoven, Netherlands. ${ }^{4}$ Department of Public Health, Academic Medical Center, University of Amsterdam, Amsterdam, Netherlands. ${ }^{5}$ Department of International Health, Research School of Primary Care and Public Health, Maastricht University, Maastricht, Netherlands.}

Received: 3 October 2012 Accepted: 22 February 2013 Published: 27 February 2013

\section{References}

1. Kickbusch I, Nutbeam D: Advancing health literacy: a global challenge for the 21st century. Health Promot Int 2000, 15(3):183-184.

2. Nutbeam D: Health literacy as a public health goal: a challenge for contemporary health education and communication strategies into the 21st century. Health Promot Int 2000, 15(3):259-267.

3. Chinn D: Critical health literacy: A review and critical analysis. Soc Sci Med 2011, 73(1):60-67.

4. Rudd RE: Health literacy skills of U.S. adults. Am J Health Behav 2007, 31(Suppl 1):8-18.

5. Lee SY, Tsai TI, Tsai YW, Kuo KN: Health literacy, health status, and healthcare utilization of Taiwanese adults: results from a national survey. BMC Publ Health 2010, 10:614.

6. Paasche-Orlow MK, Parker RM, Gazmararian JA, Nielsen-Bohlman LT, Rudd RR: The prevalence of limited health literacy. J Gen Intern Med 2005, 20(2):175-184

7. Nutbeam D: The evolving concept of health literacy. Soc Sci Med 2008 67(12):2072-2078

8. Baker DW: The meaning and measure of health literacy. J Gen Intern Med 2006, 21(8):878-883.
9. Pleasant A: A tale of two health literacies: public health and clinical approaches to health literacy. Health Promot Int 2008, 23(2):152-159.

10. Ishikawa $H$, Yano E: Patient health literacy and participation in the healthcare process. Health Expect 2008, 11(2):113-122.

11. Ad Hoc Committee on Health Literacy for the Council on Scientific Affairs, American Medical Association: Health literacy: report of the council on scientific affairs. JAMA 1999, 281(6):552-557.

12. Alliance for Health and the Future, International Longevity Centre (UK): Navigating health: the role of health literacy. London: Navigating health: the role of health literacy; 2006. http://www.ccl-cca.ca/pdfs/HealthLiteracy/ HealthLiteracyinCanada.pdf.

13. Canadian Council on Learning: Health literacy in Canada: Initial results from the International Adult Literacy and Skills Survey 2007. Ottawa: Health literacy in Canada: Initial results from the International Adult Literacy and Skills Survey 2007; 2007. http://www.ccl-cca.ca/pdfs/HealthLiteracy/ HealthLiteracyinCanada.pdf.

14. Barber MN, Staples M, Osborne RH, Clerehan R, Elder C, Buchbinder R: Up to a quarter of the Australian population may have suboptimal health literacy depending upon the measurement tool: results from a population-based survey. Health Promot Int 2009, 24(3):252-261.

15. Wang J, Schmid MR, Thombs BD: The Swiss health literacy survey: development and psychometric properties of a multidimensional instrument to assess competencies for health. Health Expect 2012. doi:10.1111/j.13697625.2012.00766.x.

16. HLS-EU Consortium: Comparative report of health literacy in eight EU member states. The European Health Literacy Survey HLS-EU. 2012. Online publication: http://www.health-literacy.eu.

17. Sørensen K, Van den Broucke S, Fullam J, Doyle G, Pelikan J, Slonska Z Brand H, for (HLS-EU) Consortium Health Literacy Project European: Health literacy and public health: A systematic review and integration of definitions and models. BMC Publ Health 2012, 12(1):80.

18. Davis TC, Long SW, Jackson RH, Mayeaux EJ, George RB, Murphy PW, Crouch MA: Rapid estimate of adult literacy in medicine: a shortened screening instrument. Fam Med 1993, 25(6):391-395.

19. Weiss BD, Mays MZ, Martz W, Castro KM, DeWalt DA, Pignone MP, Mockbee J, Hale FA: Quick assessment of literacy in primary care: the newest vital sign. Ann Fam Med 2005, 3(6):514-522.

20. Parker RM, Baker DW, Williams MV, Nurss JR: The test of functional health literacy in adults: a new instrument for measuring patients' literacy skills. J Gen Intern Med 1995, 10(10):537-541.

21. Gazmararian JA, Baker DW, Williams MV, Parker RM, Scott TL, Green DC, Fehrenbach SN, Ren J, Koplan JP: Health literacy among Medicare enrollees in a managed care organization. JAMA 1999, 281(6):545-551.

22. Rothman RL, Housam R, Weiss H, Davis D, Gregory R, Gebretsadik T, Shintani A, Elasy TA: Patient understanding of food labels: the role of literacy and numeracy. Am J Prev Med 2006, 31(5):391-398.

23. Nielsen-Bohlman LPA, Kinding DA: Health Literacy: A Prescription to End Confusion. Washington DC: The National Academies Press; 2004.

24. Ishikawa H, Nomura K, Sato M, Yano E: Developing a measure of communicative and critical health literacy: a pilot study of Japanese office workers. Health Promot Int 2008, 23(3):269-274.

25. Singh-Manoux A, Marmot MG, Adler NE: Does subjective social status predict health and change in health status better than objective status? Psychosom Med 2005, 67(6):855-861

26. Baker DW, Parker RM, Williams MV, Clark WS: Health literacy and the risk of hospital admission. J Gen Intern Med 1998, 13(12):791-798.

27. Schillinger D, Grumbach K, Piette J, Wang F, Osmond D, Daher C, Palacios J, Diaz Sullivan G, Bindman AB: Association of health literacy with diabetes outcomes. JAMA 2002, 288(4):475-482.

28. Berkman ND, Sheridan SL, Donahue KE, Halpern DJ, Crotty K: Low health literacy and health outcomes: an updated systematic review. Ann Intern Med 2011, 155(2):97-107

29. European Commission Methodology - Instrument description. http://ec.europa. eu/public opinion/description en.htm.

30. Fullam J, Doyle G, Sorensen K, Van den Broucke S, Kondilis B: The development and validation of the European health literacy survey (hls. eu). Ir J Med Sci 2011, 108:225-226.

31. Van Buuren S: Flexible Imputation of Missing Data. Boca Raton: Chapman \& Hall/CRC Press; 2012

32. R Development Core Team: $R$ : A language and environment for statistical computing. Vienna: R Foundation for Statistical Computing; 2008. 
33. Sterne JAC, White IR, Carin JB, Spratt M, Royston P, Kenward MG, Wood AM, Carpenter JR: Multiple imputation for missing data in epidemiological and clinical research: potential and pitfalls. BMJ 2009, 338:b2393.

34. Klebanoff MA, Cole SR: Use of multiple imputation in the epidemiologic literature. Am J Epidemiol 2008, 168(4):355-357.

35. Centraal Bureau voor de Statistiek. http://www.cbs.nl/nl-NL/menu/cijfers/ cijfers-per-thema/default.htm.

36. Davis TC, Arnold C, Berkel HJ, Nandy I, Jackson RH, Glass J: Knowledge and attitude on screening mammography among low-literate, low-income women. Cancer 1996, 78(9):1912-1920.

37. Peterson NB, Dwyer KA, Mulvaney SA, Dietrich MS, Rothman RL: The influence of health literacy on colorectal cancer screening knowledge, beliefs and behavior. J Nat/ Med Assoc 2007, 99(10):1105-1112.

38. Gazmararian JA, Kripalani S, Miller MJ, Echt KV, Ren J, Rask K: Factors associated with medication refill adherence in cardiovascular-related diseases: a focus on health literacy. J Gen Intern Med 2006, 21:1215-1221.

39. Baker DW, Gazmararian JA, Sudanoa J, Pattersond M: The association between Age and health literacy among elderly persons. J Gerontol B Psychol Sci Soc Sci 2000, 55(6):S368-S374.

40. St Leger L: Schools, health literacy and public health: possibilities and challenges. Health Promot Int 2001, 16(2):197-205.

41. Hibbard JH, Stockard J, Mahoney ER, Tusler M: Development of the patient activation measure (PAM): conceptualizing and measuring activation in patients and consumers. Health Serv Res 2004, 39:1005-1026.

42. Hibbard JH, Peters E, Dixon A, Tusler M: Consumer competencies and the use of comparative quality information: it isn't just about literacy. Med Care Res Rev 2007, 64(4):379-394.

43. Netherlands Interdisciplinary Demographic Institute (NIDI). http://mimosa gedap.be/Documents/stock country of birth.zip.

doi:10.1186/1471-2458-13-179

Cite this article as: van der Heide et al:: Health literacy of Dutch adults: a cross sectional survey. BMC Public Health 2013 13:179.

\section{Submit your next manuscript to BioMed Central and take full advantage of:}

- Convenient online submission

- Thorough peer review

- No space constraints or color figure charges

- Immediate publication on acceptance

- Inclusion in PubMed, CAS, Scopus and Google Scholar

- Research which is freely available for redistribution 